\title{
International Field Emission Society Becomes MRS Affiliated Organization
}

The International Field Emission Society (IFES), a professional association established to promote progress in the science, education, and technological application of field emission and related phenomena, has been accepted as a member of the Materials Research Society's Affiliated Organization Program. The Program was established in 1989 to initiate and recognize cooperative interactions with other organizations concerned with materials research (see the August 1989 MRS Bulletin, p. 52).

IFES holds annual international symposia dealing with all topics related to the theory and application of field electron emission; field ion emission; field electron microscopy; field ion microscopy; electron, ion, and liquid-metal sources; field ion mass spectrometry; and atom probe microanalysis. Symposium proceedings, previously published in the Colloquium Series of Joumal de Physique, are now available through the journal Surface Science.

A second and increasingly important IFES activity is the collection and dissemination of bibliographic information on field emission topics. Printed bibliographies are available for field ion microscopy and related techniques (1951-1978), atom probe microanalysis (1978-1987), field ion microscopy (1988), field electron microscopy (1989), and focused ion beam technology (1955-1990). Work is also progressing on a comprehensive bibliography of field electron emission phenomena. An extended version of the focused ion beam bibliography, including subject keyboarding, is available on computer disk. Other bibliographies may be available in this form in one or two years.

This year, the 38th International Field Emission Symposium will take place at the Hotel Chateau Wilhelminenberg in Vienna, Austria, August 5-9. Contributions are solicited in the areas of field electron microscopy, field ion microscopy, scanning tunneling microscopy, field ionization

\section{8th International Field Emission Symposium} International Field Emission Society

Hotel Château Wihelminenberg, Vienna, Austria, August 5-9, 1991

This symposium will deal with all topics related to the theory and application of field emission, field ionization, and field desorption. Special emphasis will be placed on investigations on field electron emission and transport phenomena in solids relating to vacuum microelectronic devices.

Contributions are solicited in the areas of:

- Field electron microscopy

- Field ion microscopy

- Scanning tunneling microscopy

- Field ionization mass spectrometry

- Atom probe microanalysis

- Ion and liquid-metal sources

The deadline for abstracts is May 1, 1991. For further information about the meeting and submission of papers, contact:

Dr. Johannes Mitterauer, Symposium Chairman

38th IFES

Institut für Allgemeine Elektroteknik und Electronik

Technische Universität Wien

Gusshausstrasse 27-29

A-1040 Wien, Austria

Phone: 43-222-58801-3870

Fax: 43-222-505-2666

Telex: 131000 tvfaw a

E-mail: PASCHKE@EAECL1.AC.AT mass spectrometry, atom probe microanalysis, and electron, ion, and liquid-metal sources. Special emphasis at the meeting will be placed on field electron emission and transport phenomena in solids relating to vacuum microelectronic devices. The deadline for abstracts is May 1, 1991.

The 1992 meeting will take place August 9-14 in Halifax, Nova Scotia.

For more information about IFES, con- tact: George D.W. Smith, President, IFES, Department of Materials, Oxford University, Parks Road, Oxford, OX1 3PH, England; phone 44-865-273762; fax 44-865273789.

MRS is pleased to be affiliated with IFES, and continually seeks cooperation with organizations which would further the interdisciplinary efforts of materials science and technology.

\section{Participants in the MRS Affiliated Organization Program}

Florida Advanced Materials Chemistry Conference - Advanced Materials Conference of the Advanced Materials Institute - International Field Emission Society - Materials Education Council - New England Society of Electron Microscopy

For more information about the MRS Affiliated Organization Program, contact David Sours at MRS: phone (412) 367-3003; FAX (412) 367-4373. 